\title{
Ocular penetration of fluorometholone-loaded PEG-PLGA nanoparticles functionalized with cell-penetrating peptides
}

\author{
Roberto Gonzalez-Pizarro1,5, Graziella Parrotta3 ${ }^{3}$ Rodrigo Vera ${ }^{2,6,7}$, Elena \\ Sánchez-López ${ }^{1,4,5}$, Ruth Galindo', Frank Kjeldsen³, Josefa Badia2,6,7, Laura Baldoma ${ }^{2,6,7}$, \\ Marta Espina ${ }^{1,5}$ \& María L García*,1,4,5 \\ ${ }^{1}$ Department of Pharmacy, Pharmaceutical Technology \& Physical Chemistry, Faculty of Pharmacy \& Food Sciences, University of \\ Barcelona, 08028 Catalonia, Spain \\ ${ }^{2}$ Department of Biochemistry \& Physiology, Faculty of Pharmacy \& Food Sciences, University of Barcelona, 08028 Catalonia, Spain \\ ${ }^{3}$ Department of Biochemistry \& Molecular Biology, Faculty of Science, University of Southern Denmark, 5230 Southern Denmark, \\ Denmark \\ ${ }^{4}$ Biomedical Research Networking Center in Neurodegenerative Diseases (CIBERNED), 28031 Madrid, Spain \\ ${ }^{5}$ Institute of Nanoscience \& Nanotechnology (IN2UB), University of Barcelona, 08028 Catalonia, Spain \\ ${ }^{6}$ Institute of Biomedicine, University of Barcelona (IBUB), 08028 Catalonia, Spain \\ ${ }^{7}$ Institut de Recerca Sant Joan de Déu (IRSJD), 08950 Catalonia, Spain \\ *Author for correspondence: marisagarcia@ub.edu
}

\begin{abstract}
Aim: Development of fluorometholone-loaded PEG-PLGA nanoparticles (NPs) functionalized with cellpenetrating peptides (CPPs) for the treatment of ocular inflammatory disorders. Materials \& methods: Synthesized polymers and peptides were used for elaboration of functionalized NPs, which were characterized physicochemically. Cytotoxicity and ability to modulate the expression of proinflammatory cytokines were evaluated in vitro using human corneal epithelial cells (HCE-2). NPs uptake was assayed in both in vitro and in vivo models. Results: NPs showed physicochemical characteristics suitable for ocular administration without evidence of cytotoxicity. TAT-NPs and G2-NPs were internalized and displayed anti-inflammatory activity in both HCE-2 cells and mouse eye. Conclusion: TAT-NPs and G2-NPs could be considered a novel strategy for the treatment of ocular inflammatory diseases of the anterior and posterior segment.
\end{abstract}

First draft submitted: 17 May 2019; Accepted for publication: 11 October 2019; Published online:

26 November 2019

Keywords: cell-penetrating peptides $\bullet$ drug delivery $\bullet$ fluorometholone $\bullet$ ocular anti-inflammatory $\bullet$ polymeric NPs

Uveitis is one of the most common intraocular inflammatory diseases affecting the anterior and posterior segments of the eye. Corticosteroid eye drops such as fluorometholone (FMT) are used in the clinic for the treatment of anterior uveitis, such as iritis, cyclitis or iridocyclitis. The main disadvantage of eye drops dosage forms is the dilution and elimination by the tear turnover, which reduces the precorneal residence time of the formulation. This would lead to limited pharmacological effect in the anterior segment of the eye [1-3]. In ocular diseases affecting the posterior segment, more invasive methods such as intravitreal injections or implants are necessary to achieve an effective pharmacological effect. These methods would result in a recurrence of undesirable side effects and make adherence to treatment difficult [4]. In addition, benzalkonium chloride (used as a preservative in most ophthalmic suspensions) has been reported to affect the tear film and the surface of the cornea, causing dryness and eye irritation [5,6]. Although most ocular corticosteroids induce glaucoma by increasing intraocular pressure in prolonged treatment, FMT has a significantly lower risk of causing this disease [7-9]. Nowadays, new strategies such as the encapsulation of corticosteroids in polymeric nanoparticles (NPs) of average size smaller than $300 \mathrm{~nm}$ and nanostructured gels have shown their capacity to increase the precorneal residence time and reach tissues of the posterior segment of the eye [10-14]. Moreover, the objective in ocular pharmacotherapy is to prevent drug 
inactivation by cytochrome P450, and its elimination by efflux transports and multidrug resistance proteins [15,16]. Therefore, the new nanostructured systems should protect the drug and allow internalization in ocular cells avoiding its elimination by both molecular (metabolizing enzymes) and anatomical (tear turnover and dilution) mechanisms. With regard to the previous approach, cell-penetrating peptides (CPPs) constitute a new strategy that would allow the internalization of nanostructured systems such as NPs. CPPs are sequences of less than 30 amino acids, rich in arginine (Arg) residues and positively charged. The use of CPPs on the surface of the NPs improve their penetration through cell membranes using various mechanisms such as direct translocation or receptor-mediated endocytosis. This allows a greater pharmacological effect of the encapsulated component than NPs without CPPs on their surface [17]. CPPs such as Penetratin (pAntp 43-58) and the transcriptional activator peptide sequence $\left(\mathrm{TAT}_{49-57}\right.$ ) of HIV-1 have been shown to be effective for the cellular internalization of polypeptides and the transfection of nucleic acids. Besides, many of the CPPs share characteristics with antimicrobial peptides, such as cationic sequences with multiple Arg residues [18-20]. Within the antimicrobial peptide group, the peptide sequence G2 has antiviral activity against the herpes simplex virus and has been shown to have the ability to internalize drugs inside cells [21-25].

In the current study, FMT-loaded maleimide-PEG-PLGA NPs (FMT-m-PEG-PLGA-NPs) functionalized with CPPs (TAT $49-57$, pAntp 43-58 and G2) have been developed to improve the anti-inflammatory efficacy of FMT in the anterior and posterior segment of the eye. The maleimide-PEG-PLGA (m-PEG-PLGA) polymer was synthesized and characterized by nuclear magnetic resonance (H-NMR), x-ray diffraction spectroscopy (XRD) and Fourier transform infrared spectroscopy (FTIR). On the other hand, the synthesized peptides, TAT $49-57$, pAntp $_{43-58}$ and G2, were analyzed by mass spectrometry. The physicochemical properties and the degree of conjugation of FMT-m-PEG-PLGA-NPs with each CPP were studied. Cytotoxicity, inhibition of proinflammatory cytokines and uptake assays (in vitro and in vivo) were carried out to provide evidence of the innocuousness and effectiveness of functionalized NPs as a new strategy in the treatment of ocular inflammatory conditions.

\section{Materials \& methods}

Materials

FMT and PLGA RG 503H were purchased from Capot Chemical (Hangzhou, China) and Evonik Corporation (AL, USA), respectively. Maleimide-PEG-NH $\mathrm{NH}_{2}(\mathrm{~m}-\mathrm{PEG})(5 \mathrm{KDa})$ was obtained from Nanosoft Polymers (Nanosoft Biotechnology LLC, NC, USA). Ethyl-3-(3-dimethylaminopropyl)carbodiimide (EDC), N-hydroxysuccinimide (NHS), N-diisopropylethylamine (DIEA), rhodamine 110 (Rho) chloride, poly(vinyl alcohol) (PVA), insulin, hydrocortisone, trypsin-EDTA (1X), lipopolysaccharide (LPS) and tetrazolium bromide (MTT) were purchased from Sigma Aldrich (MO, USA). Isoptoflucon $\AA$, FMT ophthalmic commercial drug (excipients: benzalkonium chloride, polysorbate 80 , sodium phosphate, disodium phosphate, sodium chloride, hydrochloric acid, sodium hydroxide, PVA, disodium edetate, hypromellose and purified water) was purchased in a community pharmacy (Barcelona, Spain). Keratinocyte serum-free medium, human recombinant epidermal growth factor, bovine pituitary extract, penicillin, streptomycin, fetal bovine serum, IL-1 $\beta$, IL-6, IL-8 and TNF- $\alpha$ Human ELISA Kit were acquired from Thermo Fisher Scientific (Life Technologies, CA, USA). Human corneal epithelial cell line immortalized with

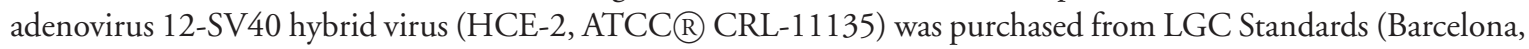
Spain). Amino acids and NovaSyn TGR resin were obtained from Novabiochem (Hohenbrunn, Germany). Water through Millipore $\AA$ MilliQ system was used for all the experiments and all the other reagents were of analytical grade.

\section{Synthesis of the polymers Rho-PLGA \& m-PEG-PLGA}

A total of $33.3 \mu \mathrm{mol}$ of PLGA RG 503H $(1.0 \mathrm{~g})$ were dissolved in $3 \mathrm{ml}$ of chloroform, then allowed to react with $234.6 \mu \mathrm{mol}$ of NHS $(27 \mathrm{mg})$ and EDC $(45 \mathrm{mg})$ overnight under continuous stirring in a sealed glass vial. Subsequently, PLGA RG $503 \mathrm{H}$ (NHS-PLGA) was activated, precipitated with $10 \mathrm{ml}$ of cold diethyl ether and centrifuged at 4000 r.p.m for $10 \mathrm{~min}$ at $20^{\circ} \mathrm{C}$. The supernatant was removed, the recovered polymer was dissolved in $3 \mathrm{ml}$ of chloroform and precipitated with cold diethyl ether. This washing/precipitation cycle was carried out three times. The NHS-PLGA obtained was dried using nitrogen gas $\left(\mathrm{N}_{2}\right)$ and then lyophilized and stored at $-20^{\circ} \mathrm{C}$.

A total of $33.2 \mu \mathrm{mol}$ of NHS-PLGA (1.0 g), $35 \mu \mathrm{mol}$ of m-PEG $(167 \mathrm{mg})$ or Rho (12.78 mg) were dissolved in $3 \mathrm{ml}$ of chloroform with $234.3 \mu \mathrm{mol}$ of DIEA and left to react overnight under continuous stirring. The obtained polymer was subjected to three washing/precipitation cycles using an 80/20 mixture of diethyl ether/cold methanol. At last, the polymer was lyophilized and stored at $-20^{\circ} \mathrm{C}$. The yield obtained from polymers (m-PEG-PLGA and 
Rho-PLGA) was calculated by the following equation:

$$
\text { Yield }(\%)=\frac{\text { weight of }(\mathrm{m}-\mathrm{PEG}-\mathrm{PLGA})}{\text { weight of }(\mathrm{NHS}-\mathrm{PLGA}+\mathrm{m}-\mathrm{PEG})} \times 100
$$

To follow the synthesis of the polymer and changes in its molecular structure, it was analyzed by H-NMR. PLGA RG 503H, NHS-PLGA, m-PEG, m-PEG-PLGA and Rho-PLGA were dissolved in deuterated dimethyl sulfoxide $\left(D M S O-\mathrm{d}_{6}\right)$. The spectrum was recorded at $298 \mathrm{~K}$ on a Varian VNMRS $400 \mathrm{MHZ}$ spectrometer (Agilent Technologies, CA, USA). To calculate the PEGylation efficiency and percentage of mass relative (MR) of the m-PEG bound to the NHS-PLGA polymer, the following equations were used $[17,26]$ :

$$
\begin{gathered}
\text { PEGylation efficiency }(\%)=\frac{\operatorname{IP}_{\mathrm{PEG}}(\delta=3.31) / \mathrm{n}}{\sum \operatorname{IP}_{\mathrm{PLGA}}(\delta=5.21 ; 4.90 ; 3.31) / \mathrm{n}} \times 100 \\
\mathrm{MR}(\%)=\frac{\operatorname{MW}_{\mathrm{PEG}}\left[\operatorname{IP}_{\mathrm{PEG} / \mathrm{n}}\right]}{\mathrm{MW}_{\mathrm{PLGA}}\left[\operatorname{IP}_{\mathrm{PLA}, \delta=5.21 / \mathrm{n}]} \times 100\right.}
\end{gathered}
$$

MW: molecular weight. PEG $=42.04 \mathrm{~g} \cdot \mathrm{mol}^{-1}, \mathrm{PLGA}=130.10 \mathrm{~g} \cdot \mathrm{mol}^{-1}$.

IP: Integration peak.

n: number of protons PLGA $=6{ }^{+} \mathrm{H}\left[\mathrm{PLA}(\delta=5.21)=1{ }^{+} \mathrm{H}\right.$; PGA $(\delta=4.90)=2{ }^{+} \mathrm{H}$; PLA $\left.(\delta=1.47)=3{ }^{+} \mathrm{H}\right]$ and PEG $(\delta=3.31)=4^{+} \mathrm{H}$.

\section{Structural studies of polymers}

The molecular changes of the synthesized polymer and its crystalline or amorphous state were evaluated by FTIR and XRD. FTIR spectra of polymers separately were obtained using a Thermo Fisher Scientific Nicolet iZ10 with an ATR diamond and DTGS detector. The scanning range was $525-4000 \mathrm{~cm}^{-1}$ [27]. The amorphous or crystalline state of NHS-PLGA, m-PEG and m-PEG-PLGA were determined by XRD measurements using Siemens D500 system (Karlsruher, Germany). X-ray powder diffractograms were recorded using $\mathrm{Cu}$ K radiation $(45 \mathrm{kV}, 40 \mathrm{~mA}$,

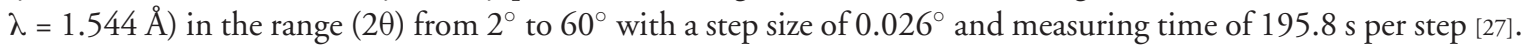

\section{Preparation \& characterization of FMT-m-PEG-PLGA-NPs}

FMT-m-PEG-PLGA-NPs and fluorescent NPs ( ${ }^{\text {Rho }} \mathrm{NPs}$ ) were prepared by the solvent displacement method [27]. Briefly, the m-PEG-PLGA $\left(10.0 \mathrm{mg} \cdot \mathrm{ml}^{-1}\right)$ and FMT $\left(0.5 \mathrm{mg} \cdot \mathrm{ml}^{-1}\right)$ were dissolved in $5 \mathrm{ml}$ of acetone. The organic phase was added slowly dropwise, under stirring, into $10 \mathrm{ml}$ of an aqueous solution of PVA $\left(15 \mathrm{mg} \cdot \mathrm{ml}^{-1}\right)$ adjusted to $\mathrm{pH}$ 4.0. Subsequently, the organic solvent was evaporated under reduced pressure. At last, the PVA was eliminated by ultracentrifugation (30,000 r.p.m for $30 \mathrm{~min}$ ) and resuspended in $10 \mathrm{ml}$ of phosphate buffered saline (PBS). The same amounts of polymer (20 mg of Rho-PLGA and $80 \mathrm{mg}$ of $\mathrm{m}$-PEG-PLGA) and FMT were used for the synthesis of ${ }^{\text {Rho NPs. }}$

Morphometry (average particle size $[\mathrm{Zav}]$ and polydispersity index [PI] measured from scattering intensity) and $\zeta$-potential (ZP) of NPs were determined in a Zetasizer NanoZS (Malvern Instruments, Malvern, UK) by dynamic light scattering and electrophoretic mobility, respectively. Samples were diluted in MilliQ water (1:10) and experiments were performed with disposable capillary cells DTS1070 (Malvern Instruments) at $25^{\circ} \mathrm{C}$. The reported values correspond to the mean $\pm \mathrm{SD}$.

The entrapment efficiency (EE) of FMT in the NPs was quantified indirectly by measuring the nonentrapped drug in the dispersion medium. The free FMT was separated by a filtration/centrifugation technique (1:10 dilution) at $25^{\circ} \mathrm{C}$ and 5000 r.p.m for $10 \mathrm{~min}$. The $\mathrm{EE}$ was calculated according to the following equation:

$$
\mathrm{EE}(\%)=\frac{\mathrm{CFMT}_{0}-\mathrm{cFMT}_{1}}{\mathrm{cFMT}_{0}} \times 100
$$

where $\mathrm{cFMT}_{0}$ and $\mathrm{CFMT}_{1}$ are the total amount of FMT and free FMT in the filtrated, respectively. Samples were evaluated by HPLC, according to the method described previously [27]. Data were processed using Empower $3 \AA$ software. 


\section{Synthesis of CPPs}

The peptide sequences, TAT 49-57 (CGGGRKKRRQRRR), pAntp43-58 (CGGGRQIKIWFQNRRMKWKK) and G2 (CGGGMPRRRRIRRRQK) were synthesized by automated solid-phase parallel peptide synthesizer (ResPep, Intavis AG, Aachen, Germany) using NovaSyn TGR resin $\left(0.25 \mathrm{mmol} \cdot \mathrm{g}^{-1}\right)$ and 9-fluorenylmethoxycarbonyl (Fmoc) strategy. Couplings were carried out with benzotriazol-1-yl-oxytripyrrolidinophosphonium hexafluorophosphate (PyBOP)/N-methylmorpholine as activator and a fivefold molar excess of Fmoc-amino acids. In order to reduce the formation of side products, a capping step was used to permanently block any unreacted amino group after the coupling reaction or to acetylate the $\mathrm{N}$-terminus of a completed peptide. Capping solution used was based on a ratio of 1:1:3 of acetic anhydride $\left(\mathrm{Ac}_{2} \mathrm{O}\right)$, DIEA and $\mathrm{N}, \mathrm{N}$ dimethylformamide (DMF). The Fmoc-deprotection step was performed twice with $20 \%$ piperidine in DMF for $30 \mathrm{~min}$. Synthesized peptides were exposed for $3 \mathrm{~h}$ to a solution composed of $94 \%$ trifluoroacetic acid (TFA): $1 \%$ triisopropylsylane: $2.5 \%$ dithiothreitol: $2.5 \%$ MilliQ water for the deprotection of the side chain and the cleavage from the resin. Peptides were isolated by precipitation with ice cold diethyl ether with subsequent centrifugation (3000 r.p.m for 4 min at $4^{\circ} \mathrm{C}$ ). Each peptide dissolved in $30 \%$ acetic acid in water were concentrated and dried using speed-vac system (Eppendorf AG, Hamburg, Germany). Peptides were purified using a Jupiter $\AA 3 \mu$ C18 300A column $(150 \times 4.6 \mathrm{~mm}$, Phenomenex $\AA)$ coupled to a 1260 semipreparative RP-HPLC (Agilent Technologies, CA, USA). The method used was a gradient of $90 \%$ water $(0.1 \%$ TFA $) / 90 \%$ acetonitrile $(0.1 \%$ TFA). Crude peptides were purified to a yield of $90 \%$ by RP-HPLC at $220 \mathrm{~nm}$. Desalted peptides were analyzed by matrix-assisted laser desorption ionization source/tandem time-offlight (MALDI-TOF/TOF) mass spectrometer (Ultraflextreme, Bruker Daltonik GmbH, Mannheim, Germany) using a $\alpha$-cyano-4-hydroxycinnamic acid matrix.

\section{Conjugation of CPPs with FMT-m-PEG-PLGA-NPS}

A total of $1.45 \mu \mathrm{mol}$ of FMT-m-PEG-PLGA-NPs $(5 \mathrm{ml}$ of NPs) were reacted with $1.45 \mu \mathrm{mol}$ of CPP (2.34 mg of $\mathrm{TAT}_{49-57}, 3.65 \mathrm{mg}$ of pAntp $43-58$ and $2.87 \mathrm{mg}$ of G2) overnight under magnetic stirring. Next, ultracentrifugation of the NPs was performed (28,000 r.p.m for $30 \mathrm{~min}$ at $\left.4{ }^{\circ} \mathrm{C}\right)$ to remove the peptide unconjugated and the pellet containing NPs was resuspended in PBS. In order to confirm the conjugation with the CPPs, derivatized NPs were lyophilized and analyzed by H-NMR (previously dissolved DMSO- $\mathrm{d}_{6}$ ). MR was used for the calculation of each CPP bound to FMT-m-PEG-PLGA-NPs according to the following equation [17]:

$$
\operatorname{MR}(\%)=\frac{\mathrm{MW}_{\mathrm{CPP}}\left[\mathrm{IP}_{\mathrm{CPP} / \mathrm{n}}\right]}{\mathrm{MW}_{\mathrm{PLGA}}\left[\mathrm{IP}_{\mathrm{PLA}} / \mathrm{n}\right]} \times 100
$$

MW: molecular weight. TAT $49-57=1612.94 \mathrm{~g} \cdot \mathrm{mol}^{-1}, \mathrm{pAntp}_{43-58}=2519.36 \mathrm{~g} \cdot \mathrm{mol}^{-1}, \mathrm{G} 2=1982.12 \mathrm{~g} \cdot \mathrm{mol}^{-1}$, PLGA $=130.10 \mathrm{~g} \cdot \mathrm{mol}^{-1}$.

IP: Integration peak.

n: number of protons: $\operatorname{TAT}_{49-57}(\delta=7.0-8.2 \mathrm{ppm}): 46{ }^{+} \mathrm{H}, \mathrm{pAntp}_{43-58}(\delta=6.8-8.2): 64{ }^{+} \mathrm{H}, \mathrm{G} 2(\delta=7.0-8.2)$ : $50^{+} \mathrm{H}$ and PLA $(\delta=5.21): 1^{+} \mathrm{H}$.

\section{In vitro biological studies}

Cell culture

The culture medium for HCE-2 cells was keratinocyte serum-free medium supplemented with bovine pituitary extract $0.05 \mathrm{mg} \cdot \mathrm{ml}^{-1}$ and epidermal growth factor $5 \mathrm{ng} \cdot \mathrm{ml}^{-1}$ containing insulin $0.005 \mathrm{mg} \cdot \mathrm{ml}^{-1}$, fetal bovine serum $10 \%$, hydrocortisone $500 \mathrm{ng} \cdot \mathrm{ml}^{-1}$ and penicillin $100 \mathrm{U} \cdot \mathrm{ml}^{-1}$ plus streptomycin $100 \mathrm{mg} \cdot \mathrm{ml}^{-1}$. Cells were grown on $25 \mathrm{~cm}^{2}$ culture flask to confluency $(80 \%)$ in a humidified $10 \% \mathrm{CO}_{2}$ atmosphere at $37^{\circ} \mathrm{C}$. The culture medium was changed every 3 days.

\section{Cytotoxicity study}

The effect on cell viability of NPs conjugated with each CPP was evaluated in vitro using the MTT assay. For this, $1 \times 10^{5} \mathrm{HCE}-2$ cells in $0.1 \mathrm{ml}$ were seeded in 96-well plates and incubated for $24 \mathrm{~h}$ at $37^{\circ} \mathrm{C}$. Then, cells were exposed to different drug concentrations contained in TAT-NPs, pAntp-NPs, G2-NPs and Isoptoflucon (ophthalmic commercial drug). After 24 or $48 \mathrm{~h}$ of incubation, cells were washed with PBS and incubated with $0.25 \% \mathrm{MTT}$ in fresh medium for $2 \mathrm{~h}$ at $37^{\circ} \mathrm{C}$ in dark. Subsequently, medium was removed, and cells were lysed by the addition of $99 \%$ DMSO. At last, the absorbance was measured at $\lambda=560 \mathrm{~nm}$ using an automatic Modulus ${ }^{\mathrm{TM}}$ 
Microplate Photometer (Turner BioSystems, CA, USA). The data were analyzed by calculating the percentage of MTT reduction compared with the control (untreated cells, $100 \%$ viability).

\section{Determination of proinflammatory cytokines}

To evaluate the anti-inflammatory activity of the derivatized NPs (TAT-NPs, pAntp-NPs and G2-NPs) and the commercial drug (Isoptoflucon), HCE-2 cells were seeded $\left(1 \times 10^{5} \mathrm{cell} \cdot \mathrm{ml}^{-1}\right)$ in 12 -well plates and grown until $90 \%$ confluency. The different NPs were added to the culture medium at $50 \mu \mathrm{g} \cdot \mathrm{ml}^{-1}$ (drug concentration loaded NPs) and inflammation was induced with LPS $\left(1 \mu \mathrm{g} \cdot \mathrm{ml}^{-1}\right)$. Cells stimulated only with LPS were considered the positive control and untreated cells as the negative control. After $48 \mathrm{~h}$ incubation, the supernatants were collected and centrifuged (10,000 r.p.m for $5 \mathrm{~min})$ at $4^{\circ} \mathrm{C}$ and stored at $80^{\circ} \mathrm{C}$ until use. Secreted levels of the pro-inflammatory cytokines IL-1 $\beta$, IL-6, IL- 8 and TNF- $\alpha$ were quantified by ELISA sets (BD Biosciences, CA, USA) according to manufacturer's instructions. The results were expressed as $\mathrm{pg} \cdot \mathrm{ml}^{-1}$.

\section{Cellular uptake study}

To assess internalization of NPs in HCE- 2 cells, $1 \times 10^{5}$ cell $\cdot \mathrm{ml}^{-1}$ HCE- 2 were grown in eight-well chamber slider (ibidi ${ }^{\circledR}$, Gräfelfing, Germany) until approximately $80 \%$ confluence and then incubated with $50 \mu \mathrm{g} \cdot \mathrm{ml}^{-1}$ (drug

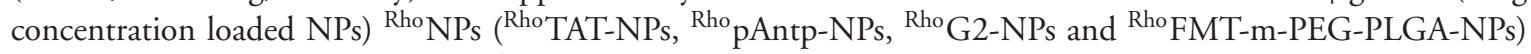

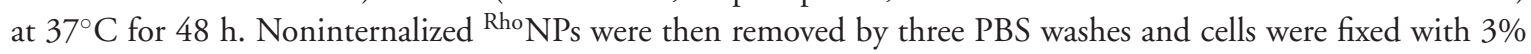
paraformaldehyde for $30 \mathrm{~min}$ at $25^{\circ} \mathrm{C}$. Afterwards, cells were washed three times with PBS and the nuclei were stained with 4',6-diamidino-2-phenylindole (DAPI) for $15 \mathrm{~min}$ at $25^{\circ} \mathrm{C}$. Finally, the cells were washed three times and mounting solution (PBS) was added for microscopic analysis. Images were acquired using a Leica TCS SP5 confocal laser scanning microscopy (Leica Microsystems, Wetzlar, Germany) with a 63x oil immersion objective lens.

\section{In vivo study: ocular uptake}

C57BL/6J wild-type male mice of 3 months of age were used. Animals were under controlled temperature, humidity and light conditions with ad lib access to food and water. Mice were treated in accordance to ethical guidelines of the European Community Council Directive 86/609/EEC and the procedures established by the Department of Agriculture, Branch and Fisheries of the Government of Catalonia (approved by the ethics committee of University of Barcelona).

Fluorescent formulations $(50 \mu \mathrm{l})$ were administered in the right eye and the contralateral eye was used as a control. After $48 \mathrm{~h}$ of treatment, all animals were sacrificed. The eyes were enucleated and fixed in $4 \%$ paraformaldehyde for $24 \mathrm{~h}$ at $4{ }^{\circ} \mathrm{C}$. Then, the samples were embedded in optimal cutting temperature compound and stored at $-40^{\circ} \mathrm{C}$. Horizontal sections of $20 \mathrm{~mm}$ were collected using a Leica CM3050s cryostat (Leica Microsystems, Wetzlar, Germany). The bright and fluorescent fields of the sections were taken by a fluorescent inverted microscope (Leica DMI4000 B).

\section{Statistical analysis}

Multiple comparisons were developed using two-way analysis of variance (ANOVA) with Tukey post hoc test with a significance of $\mathrm{p}<0.05$ after having confirmed the normality and equality of variances by Bartlett in the groups. All analyzed data were presented as mean \pm SD. GraphPad Prism 6.01 software and ImageJ was used to analyze the data and images, respectively.

\section{Results}

Synthesis of Rho-PLGA \& m-PEG-PLGA

The yield of the synthesis of the polymers Rho-PLGA and m-PEG-PLGA after lyophilization was $85.7-92.1 \%$ and 81.4-90.1\%, respectively. The H-NMR analysis identified the characteristic peaks of each polymer synthesized. Particularly, in the PLGA RG 503H the peaks are visualized at $5.21 \mathrm{ppm}$ for $\mathrm{CH}$ proton of lactide, $4.90 \mathrm{ppm}$ for $\mathrm{CH}_{2}$ proton of glycolide and $1.47 \mathrm{ppm}$ for $\mathrm{CH}_{3}$ proton of lactide (Supplementary Figure 1A). In the case of the NHS-PLGA, the same previous peaks are revealed plus a peak at $2.70 \mathrm{ppm}$ corresponding to the $\mathrm{CH}_{2}$ proton of the NHS (Supplementary Figure 1B). The polymer synthesized m-PEG-PLGA (Figure 1), showed the same peaks as the PLGA RG 503H with the presence of the characteristics of m-PEG (Supplementary Figure 1C) at $7.00 \mathrm{ppm}$ for $\mathrm{CH}$ proton of the maleimide and $3.31 \mathrm{ppm}$ for $\mathrm{CH}_{2}$ of ethylene glycol proton. In addition, the binding of 


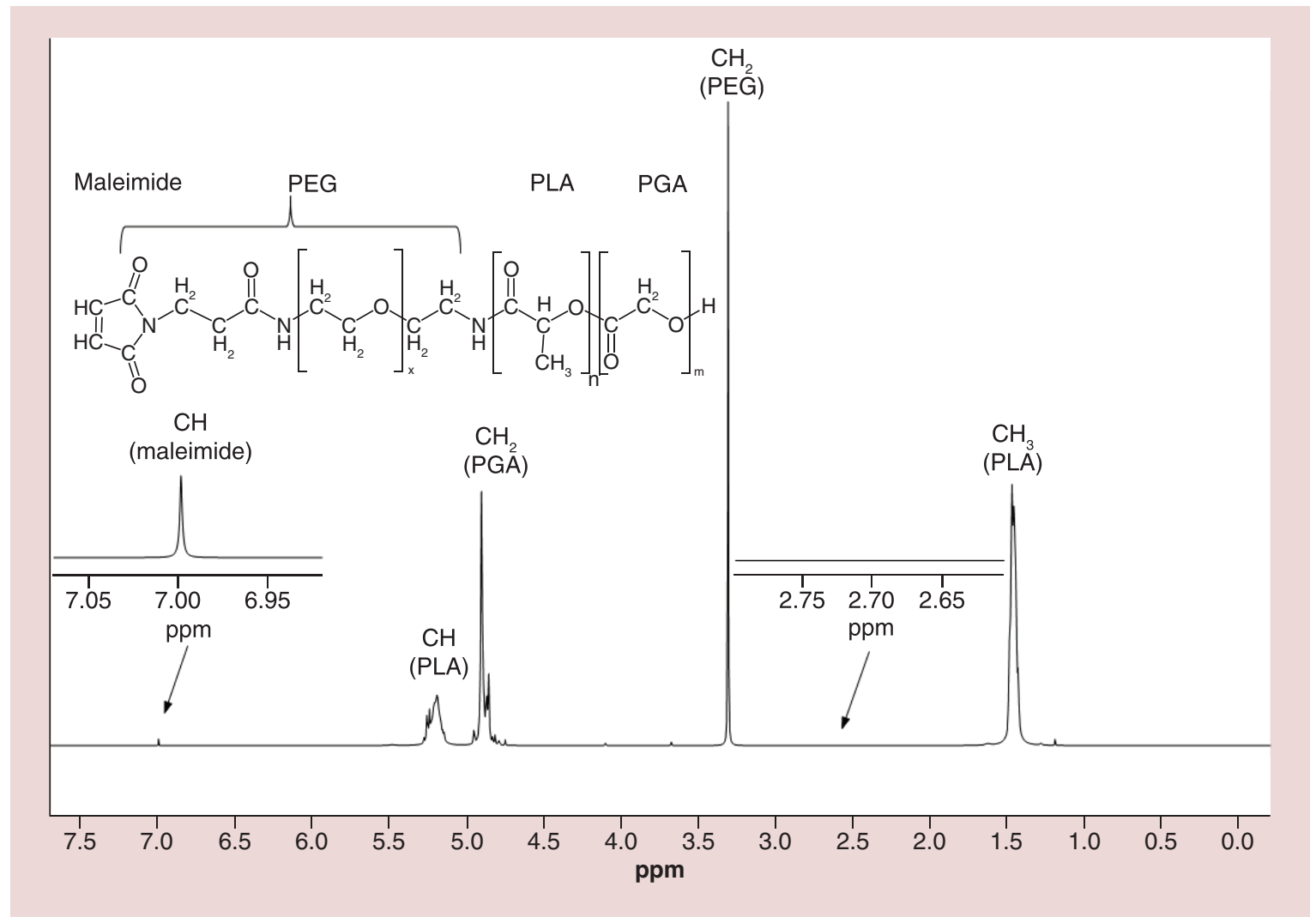

Figure 1. Nuclear magnetic resonance spectrum of m-PEG-PLGA.

m-PEG and Rho (Supplementary Figure 1D) to the NHS-PLGA polymer is confirmed by the absence of the $\mathrm{CH}_{2}$ proton NHS peak at $2.70 \mathrm{ppm}$. The PEGylation efficiency of the NHS-PLGA polymer was between 26.9 and $30.1 \%$ (MR between 7.6 and 9.0\%).

\section{Structural studies of polymers}

To investigate the degree of crystallization after the conjugation between the polymers NHS-PLGA and m-PEG, a study was carried out in XRD. In Figure 2A, it is possible to show that the polymers PLGA RG 503H, NHS-PLGA and $\mathrm{m}$-PEG-PLGA showed similar diffractograms of amorphous characteristics. In the case of m-PEG, it exhibits two peaks indicative of crystallinity at $19.15^{\circ}$ and $23.41^{\circ}(2 \Theta)$.

FTIR spectra of PLGA polymers RG 503H, NHS-PLGA, m-PEG and m-PEG-PLGA are shown in Figure 2B. The m-PEG spectrum exhibits a characteristic peak at $2877 \mathrm{~cm}^{-1}$ corresponding to the stretching vibration of $\mathrm{CH}_{2}$. The repeating $\mathrm{CH}_{2}-\mathrm{CH}_{2}-\mathrm{O}$ unit of m-PEG is visualized at 1280 (stretching of C-C-O) and $1099 \mathrm{~cm}^{-1}$ (stretching of C-O-C). The bands at 1466 and $1342 \mathrm{~cm}^{-1}$ represent $\mathrm{CH}$ bending of the m-PEG. At last, the peak at $1707 \mathrm{~cm}^{-1}$ is attributed to the $\mathrm{C}=\mathrm{O}$ of the maleimide. PLGA RG 503H, NHS-PLGA and m-PEG-PLGA are shown to present similar spectra with characteristic stretching vibration peaks at 2862-3025 $\left(\mathrm{CH}_{3}, \mathrm{CH}_{2}\right.$ and $\left.\mathrm{CH}\right)$, $1749(\mathrm{C}=\mathrm{O}), 1162(\mathrm{C}-\mathrm{O})$ and $1087 \mathrm{~cm}^{-1}$ (C-C-O). In addition, the NHS-PLGA has a wide band at $3321 \mathrm{~cm}^{-1}$ corresponding to the C-O-N of the NHS. The carbonyl groups $(\mathrm{C}=\mathrm{O})$ of the NHS are represented at peaks 1653 and $1560 \mathrm{~cm}^{-1}$.

\section{Characterization of FMT-m-PEG-PLGA-NPs}

Once the FMT-m-PEG-PLGA-NPs and Rho NPs were synthesized and resuspended in PBS, their physicochemical characteristics such as Zav, PI, ZP and EE were evaluated (Table 1). 


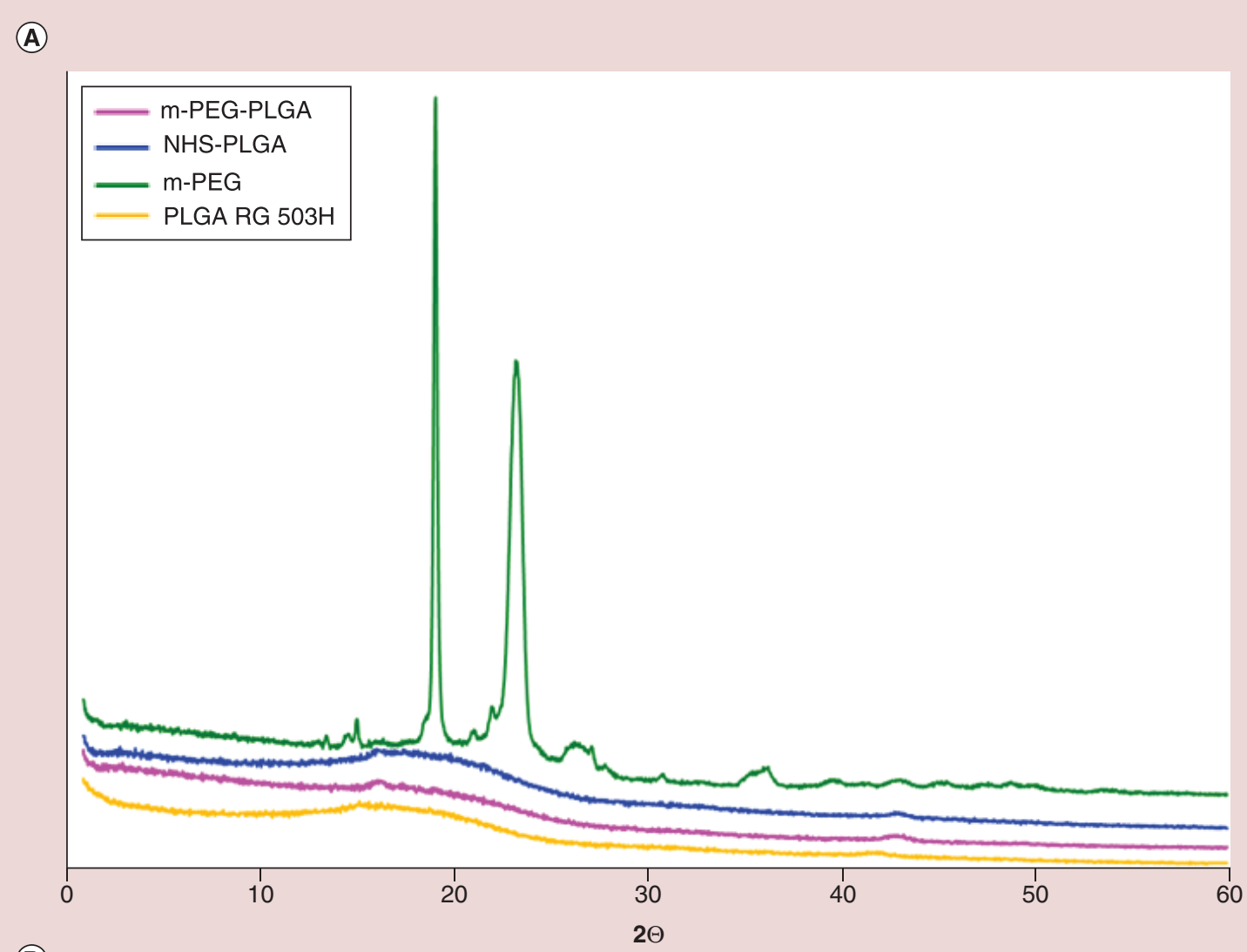

(B)

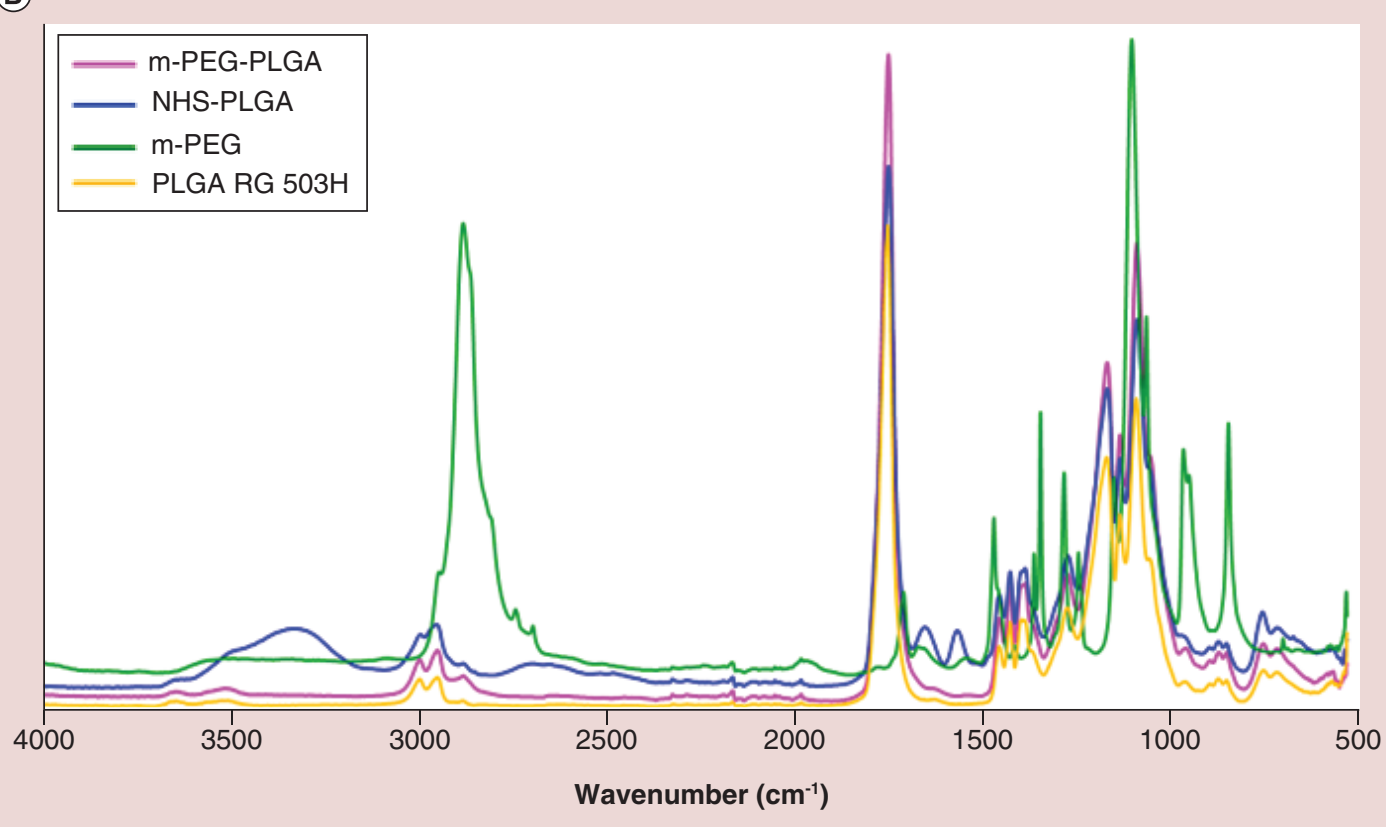

Figure 2. Structural studies of polymers. (A) XRD diffractograms. (B) FTIR spectra.

FTIR: Fourier transform infrared spectroscopy; XRD: X-ray diffraction spectroscopy. 


\begin{tabular}{|c|c|c|c|c|c|c|}
\hline Formulation & $\operatorname{Zav}(\mathrm{nm})$ & PI & $\mathrm{ZP}(\mathrm{mV})$ & EE (\%) & $\begin{array}{l}\text { Drug-loaded NPs ( } \mu \mathrm{g} \\
\text { drug/mgNPs) }\end{array}$ & $\begin{array}{l}\text { Functionalization grade } \\
(\%)\end{array}$ \\
\hline FMT-m-PEG-PLGA-NPs & $150.3 \pm 1.2$ & $0.112 \pm 0.007$ & $-8.32 \pm 0.65$ & $99.3 \pm 0.2$ & 49.7 & $\mathrm{~N} / \mathrm{A}$ \\
\hline Rho NPs & $170.9 \pm 1.3$ & $0.139 \pm 0.038$ & $-13.30 \pm 0.49$ & $98.6 \pm 0.1$ & 49.3 & $\mathrm{~N} / \mathrm{A}$ \\
\hline TAT $_{49-57}$ & $164.0 \pm 0.7$ & $0.077 \pm 0.030$ & $-0.29 \pm 0.06$ & QNPs & QNPs & 2.0 \\
\hline pAntp 43-58 & $167.2 \pm 2.6$ & $0.074 \pm 0.008$ & $0.15 \pm 0.06$ & QNPs & QNPs & 4.6 \\
\hline G2 & $169.7 \pm 2.1$ & $0.078 \pm 0.180$ & $-1.06 \pm 0.27$ & QNPs & QNPs & 0.6 \\
\hline
\end{tabular}

EE: Entrapment efficiency; N/A: Not applicable; NP: Nanoparticle; PI: Polydispersity index; QNP: Quantified in the FMT-m-PEG-PLGA-NP (EE = 99, $3 \pm 0.2 \%$; $49.7 \mu$ g drug/mg NPs); Zav: Average particle size; ZP: $\zeta$-potential.

\section{Synthesis of CPPs}

Amidated CPPs that possess in their sequence 4 glycine as a spacer and a cysteine in the $\mathrm{N}$-terminus to be linked with the maleimide were synthesized by the solid-phase method with an automatic synthesizer. The molecular weight of the CPPs with a purity of 90\% was analyzed by MALDI-TOF/TOF (Supplementary Figure 2).

\section{Conjugation of CPPs with FMT-m-PEG-PLGA-NPs}

After lyophilizing the NPs conjugated with the CPPs, these were analyzed by H-NMR (Supplementary Figure 3) in order to calculate MR (\%) in the polymer. Functionalization was calculated by integrating the aromatic and amide/amine regions of the peptides in contrast to the $\mathrm{CH}$ integration of the PLA $(\delta=5.2)$. The TAT $49-57$ were integrated amide/amine regions $(\delta=7.0-8.2 \mathrm{ppm})$ with 46 protons corresponding to amides, amines and the guanidinium side chains. The pAntp43-58 with 64 protons, the regions of the aromatic groups (tryptophan and phenylalanine) and amide/amine were integrated $(\delta=7.0-8.2)$. At last, the $\mathrm{G} 2$ with 57 protons, the corresponding amide/amine regions were integrated $(\delta=7.0-8.2)$. According to the previous analysis, the functionalization grades and physicochemical characteristics (Zav, PI and the ZP) of TAT-NPs, pAntp-NPs and G2-NPs are visualized in Table 1.

\section{Cytotoxicity study}

Toxicity of NPs on the HCE-2 cell line was evaluated at two different concentrations using the MTT viability assay. Cell viability was analyzed at 24 and $48 \mathrm{~h}$ (Figure 3). Results showed that at $24 \mathrm{~h}$, none of the NPs conjugated with CPPs was cytotoxic as cell viability was kept close to $100 \%$ when assayed both at low $\left(5 \mu \mathrm{g} \cdot \mathrm{ml}^{-1}\right)$ and high $\left(50 \mu \mathrm{g} \cdot \mathrm{ml}^{-1}\right)$ FMT concentration. At $48 \mathrm{~h}$, cell viability was reduced to about $80-90 \%$ with TAT-NPs and pAntpNPs at $5 \mu \mathrm{g} \cdot \mathrm{ml}^{-1}$ and close to $70 \%$ at $50 \mu \mathrm{g} \cdot \mathrm{ml}^{-1}$. In contrast, no toxicity was observed for G2-NPs. In this case, the increased MTT activity compared with untreated cells could be attributed to a proliferative effect of theses NPs. Cytotoxicity of Isoptoflucon eye drops (containing FMT as the active drug) was also analyzed in parallel at the same concentrations, and cell viability was of around $82 \%$ (at $5 \mu \mathrm{g} \cdot \mathrm{ml}^{-1}$ ) and $38 \%$ (at $50 \mu \mathrm{g} \cdot \mathrm{ml}^{-1}$ concentration) at $24 \mathrm{~h}$, and 72 and $28 \%$, respectively, when cells were incubated for $48 \mathrm{~h}$. These results indicate that encapsulation of FMT in NPs reduces cytotoxicity of the commercial drug, as it avoids the use of preservatives such as benzalkonium chloride or solubilizers such as polysorbate 80 , which are excipients that decrease cell viability [28,29].

\section{Evaluation of the anti-inflammatory activity of NPs}

Since LPS induces inflammation via TLR4 receptors, we sought to evaluate the capability of NPs conjugated with CPPs to inhibit the inflammatory response by analysing secreted IL- $1 \beta$, IL- 6 , IL- 8 and TNF- $\alpha$ cytokines in LPS-stimulated HCE-2 cells. Results are shown in Figure 4. In the absence of NPs (positive control) LPS induced a significant increase in all cytokines analyzed. The TAT-NPs, pAntp-NPs and G2-NPs significantly decreased the expression of IL- $1 \beta$ similarly to Isoptoflucon ( $p<0.001$ ) (Figure 4A). Concerning IL-6, IL- 8 and TNF- $\alpha$, secreted levels were reduced by TAT-NPs and G2-NPs, whereas pAntp-NPs only reduced IL-8 although to a lesser extent than the other NPs (Figure 4B-D). In the case of TNF- $\alpha$ (Figure 4D), the formulation pAntp-NPs showed a greater cytokine expression than the positive control (LPS-treated cells). Overall, these results indicated that the best anti-inflammatory effect was achieved with G2-NPs. In this case, the reduction of LPS-induced cytokine levels was close to that observed for Isoptoflucon, except for IL-8. The formulations developed are in accordance with other nanostructured systems such as nanosponges, which improve the activity of the encapsulated compound in contrast to the free compound [30]. 

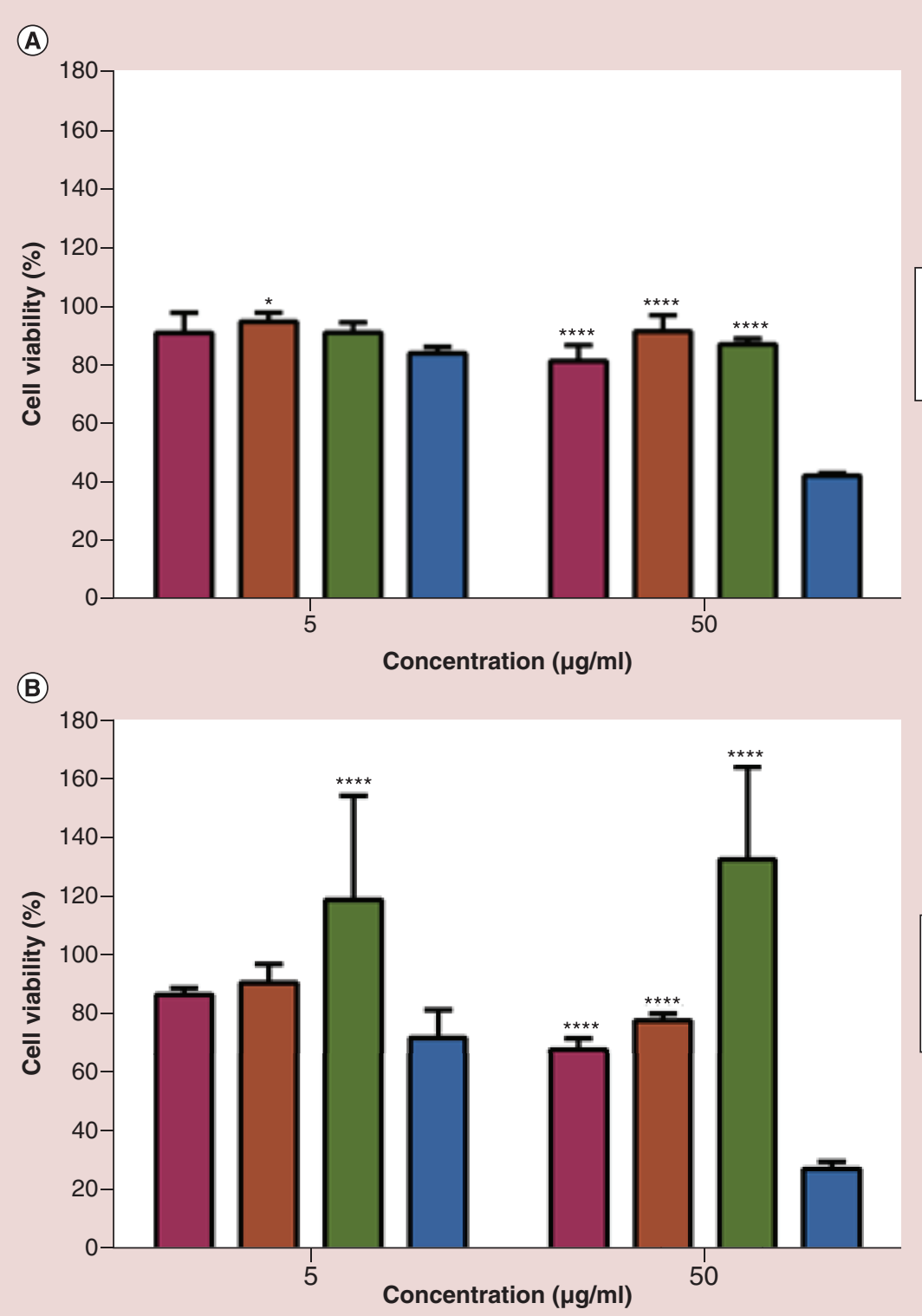

Figure 3. Effect of nanoparticles on the viability of HCE-2 cells. (A) at $24 \mathrm{~h}$, and (B) $48 \mathrm{~h}$. MTT reduction values of untreated control cells were set as $100 \%$ cell viability.

Data are expressed as mean $\pm S D$ : ${ }^{*} p<0.05 ; * * p<0.01 ; * * * p<0.001$ and $* * * * p<0.0001$ significant difference compared with Isoptoflucon ${ }^{\circledR}$ at the same concentration.

MTT: Tetrazolium bromide; NP: Nanoparticle.

\section{Cellular uptake of Rho NPs}

Cellular uptake of Rho NPs $\left(50 \mu \mathrm{g} \cdot \mathrm{ml}^{-1}\right)$ was analyzed in the HCE-2 cell line. After $48 \mathrm{~h}$ incubation, the NPassociated green fluorescence was visualized by confocal fluorescence microscopy in all cells challenged with NPs but not in the untreated control cells (Figure 5). The nucleus was visualized with DAPI. In the merged images, the ${ }^{\text {Rho }} \mathrm{NPs}$ were visualized in the cytoplasm. The formulations ${ }^{\text {Rho }}$ TAT-NPs and ${ }^{\text {Rho }} \mathrm{G} 2-\mathrm{NPs}$ yielded the stronger fluorescence signal. The analysis with Interactive 3D Surface Plot of ImageJ confirmed this fact and allowed to discern that cells treated with ${ }^{\text {Rho }}$ TAT-NPs displayed higher intensity than cells incubated with the ${ }^{\text {Rho }} \mathrm{G} 2$ NPs formulation. Intensity of fluorescence emitted by the other internalized formulations ( ${ }^{\mathrm{Rho}} \mathrm{pAntp}-\mathrm{NPs}$ and ${ }^{R h o}$ FMT-m-PEG-PLGA-NPs) was lower, without apparent accumulation within of HCE-2 cells. 
(A)

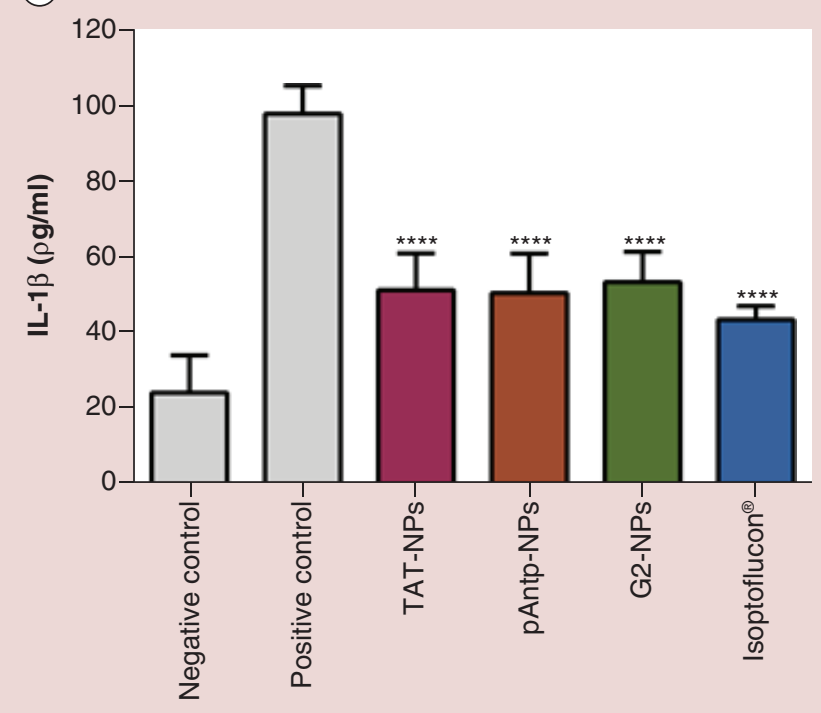

(C)

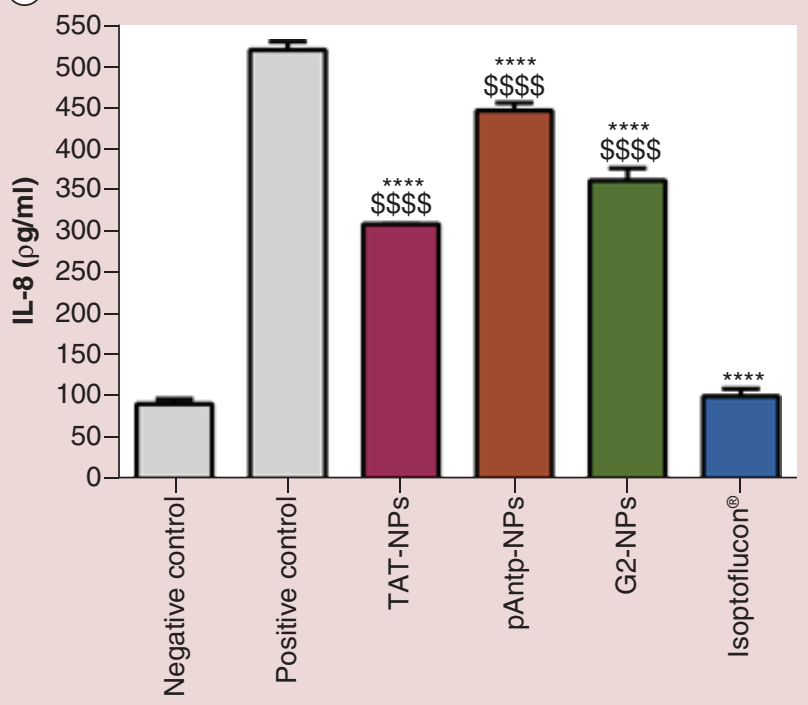

(B)

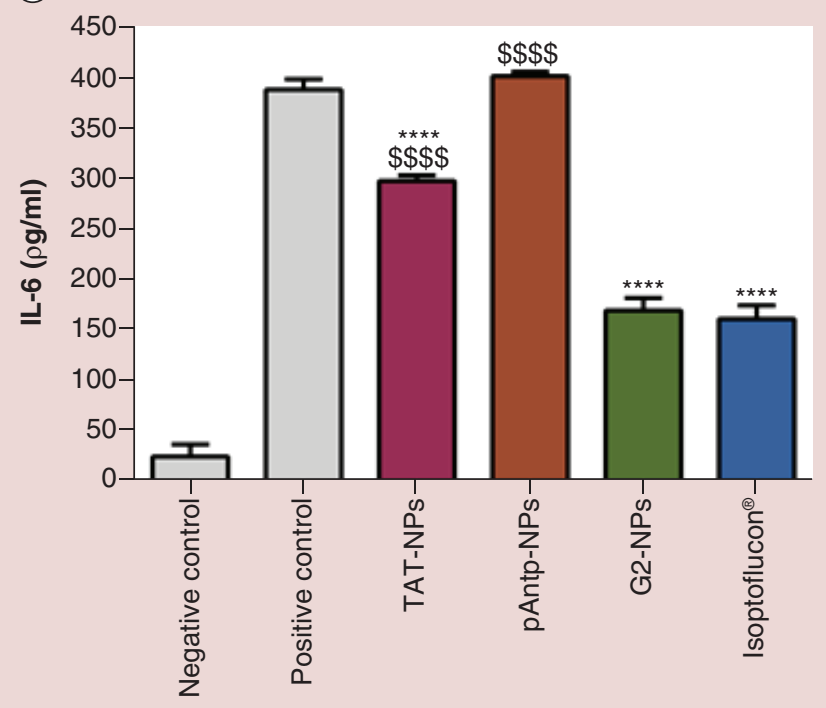

(D)

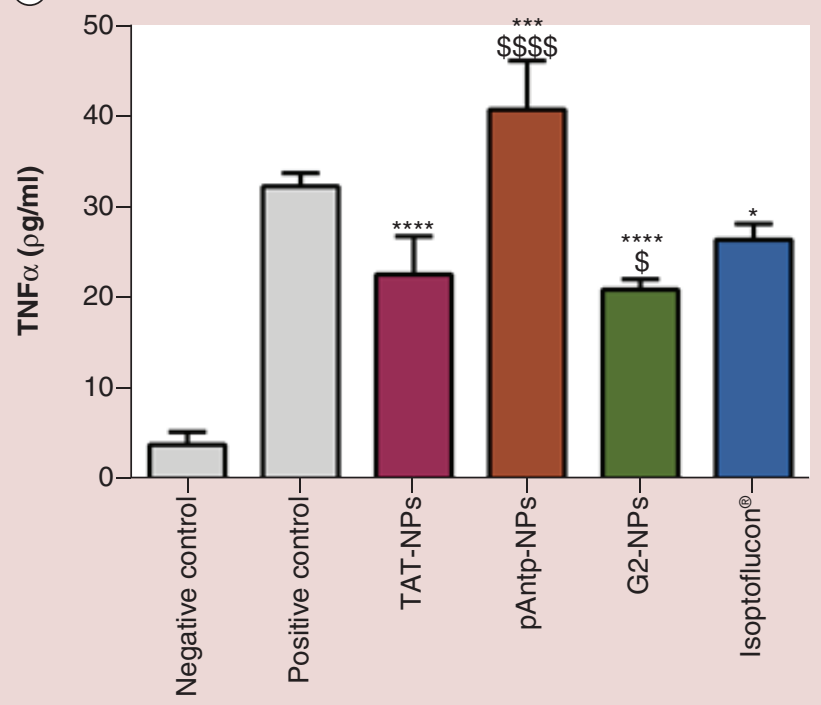

Figure 4. Quantification of secreted proinflammatory cytokines in lipopolysaccharide-stimulated HCE-2 cells incubated in the absence and presence of the indicated nanoparticles $\left(50 \mu \mathrm{g} \cdot \mathrm{ml}^{-1}\right)$ for $48 \mathrm{~h}$. (A) IL-1 $\beta$, (B) IL-6, (C) IL-8, (D) TNF- $\alpha$. Negative control: untreated control cells.

Values are expressed as mean $\pm S D: * p<0.05 ; * * p<0.01 ; * * * p<0.001$ and $* * * * p<0.0001$ significantly different compared with positive control (LPS-stimulated cells). ${ }^{\$ p}<0.05 ;{ }^{\$ \$} p<0.01 ; \$ \$ p<0.001$ and $\$ \$ \$ \$ p<0.0001$ significantly different compared with Isoptoflucon ${ }^{\circledR}$. LPS: Lipopolysaccharide; NP: Nanoparticle.

Ocular uptake of Rho NPs

After ocular treatment of C57BL/6J wild-type mice for $48 \mathrm{~h}$ with ${ }^{\text {Rho }}$ TAT-NPs, ${ }^{\text {Rho }}$ G2-NPs, ${ }^{\text {Rho }}$ pAntp-NPs and ${ }^{R h o}$ FMT-m-PEG-PLGA-NPs, the sectioned eyes were analyzed by fluorescence microscopy (Figure 6). Again, greater fluorescence was observed in both the anterior and posterior segment in samples treated with the formulations ${ }^{R h o}$ TAT-NPs and ${ }^{R h o}$ G2-NPs. The formulations ${ }^{R h o}$ pAntp-NP and ${ }^{R h o}$ FMT-m-PEG-PLGA-NPs had a greater presence in the posterior than in the anterior segment of the eye. 


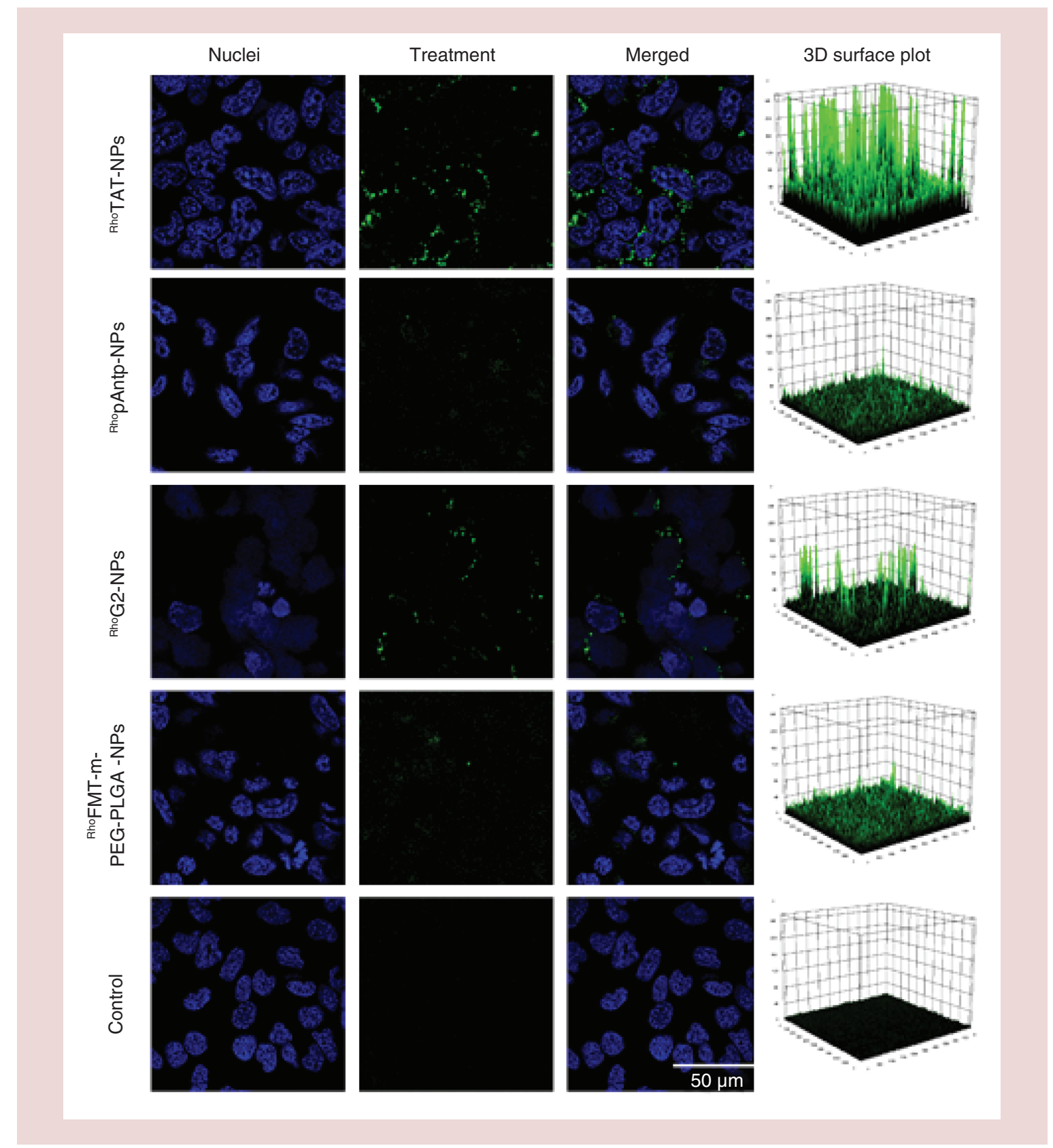

Figure 5. Cellular uptake of nanoparticles conjugated with cell-penetrating peptides. HCE-2 cells were incubated with the indicated fluorescent-labeled NPs $\left(50 \mu \mathrm{g} \cdot \mathrm{ml}^{-1}\right)$ for $48 \mathrm{~h}$ and analyzed using laser scanning confocal spectral microscope. Images are representative of three independent biological experiments. Quantification of the green signal corresponding to internalized NPs is shown by 3D surface plots.

NP: Nanoparticle.

\section{Discussion}

In the present study, the polymers Rho-PLGA and m-PEG-PLGA were successfully synthesized with high performance using the carbodiimide pathway as a conjugation strategy [31,32]. The conjugation of both Rho and $\mathrm{m}-\mathrm{PEG}$ to NHS-PLGA was confirmed by the removal of the $\mathrm{CH}_{2}$ group from the NHS in the H-NMR spectrum (Figure 1 \& Supplementary Figure 1D). Furthermore, the m-PEG moiety was identified in the PLGA due to the appearance of ethylene glycol and maleimide peaks (Figure 1), with a PEGylation degree close to 30\% (MR 9\%) [33,34]. The $\mathrm{XRD}$ and FTIR profiles confirmed the information obtained by H-NMR regarding the synthesis of the m-PEG- 


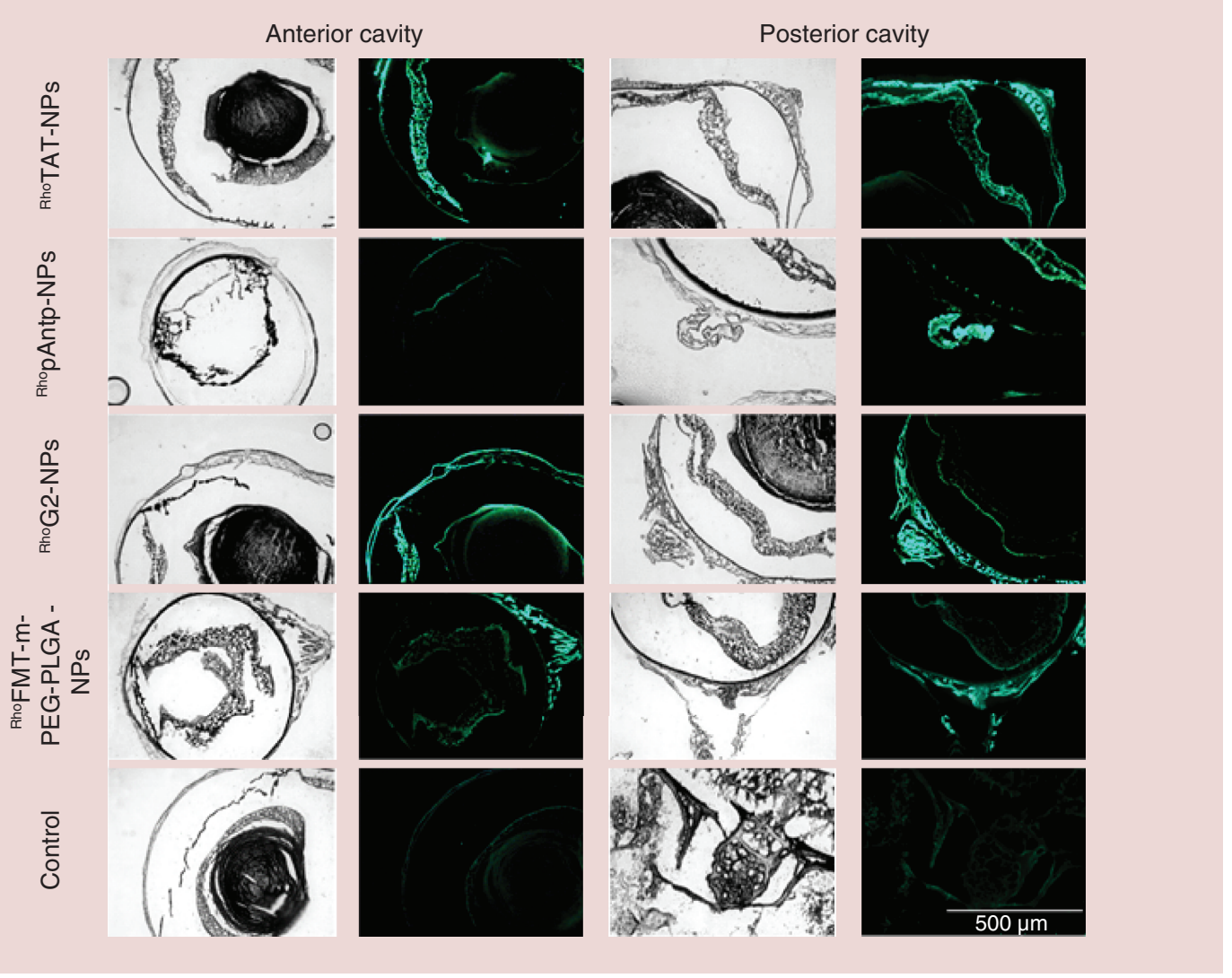

Figure 6. Ocular uptake of nanoparticles conjugated with cell-penetrating peptides. C57BL/6J wild-type male mice were treated with the indicated fluorescent-labeled NPs $\left(50 \mu \mathrm{g} \cdot \mathrm{ml}^{-1}\right)$ for $48 \mathrm{~h}$ and analyzed using fluorescent inverted microscope.

NPs: Nanoparticles.

PLGA polymer. The diffractogram of the m-PEG-PLGA (Figure 2A) showed a profile of amorphous characteristics without the presence of crystalline peaks of PEG, agreeing with other authors that the presence of less than $10 \%$ $(\mathrm{m} / \mathrm{m})$ of PEG in the polymer and its peaks are not visualized in the XRD or in the FTIR spectrum [35-37]. Despite this fact, the structural change of the NHS-PLGA to the m-PEG-PLGA was evidenced in the FTIR and H-NMR analysis by the elimination of $\mathrm{C}=\mathrm{O}$ and $\mathrm{C}-\mathrm{O}-\mathrm{N}$ peaks of the NHS, confirming the union $\mathrm{m}-\mathrm{PEG}$ to the polymer (Figure 2B). The developed FMT-m-PEG-PLGA-NPs displayed a Zav less than $150 \mathrm{~nm}$ with a monodisperse population distribution, a negative surface charge and EE close to $99 \%\left(0.5 \mathrm{mg} \cdot \mathrm{ml}^{-1}\right)$. It has been described that particles with sizes greater than $10 \mu \mathrm{m}$ could cause ocular irritation. Hence, the NPs elaborated in this study would circumvent such an effect. Moreover, the agglomeration and/or precipitation of NPs would be avoided with their negative ZP [38,39].

The CPPs TAT $49-57$, pAntp43-58 and G2 characterized by MALDI-TOF/TOF presented an $m / z$ value of 1613.296, 2520.192 and 1983.102, respectively (Supplementary Figure 2). These CPPs, properly purified and characterized, were conjugated with the FMT-m-PEG-PLGA-NPs. The monodisperses system was maintained in the final NPs and the Zav increased by an average of $17 \mathrm{~nm}$ more. Furthermore, the conjugation of the CPPs to the NPs was evidenced both by the change of the Zav and by the change of the ZP to a less negative value by the cationic characteristics of the CPPs (Table 1) [17]. Through H-NMR analysis, it was possible to calculate the MR of the functionalized CPPs in the NPs. The pAntp43-58 $(\mathrm{MR}=4.6 \%)$ was the CPP that was conjugated to a greater degree in mass followed by $\mathrm{TAT}_{49-57}(\mathrm{MR}=2.0 \%)$ and $\mathrm{G} 2(\mathrm{MR}=0.6 \%)$. These data indicate that the maleimide-cysteine conjugation pathway is a thermodynamically favorable reaction that allows the conjugation of small amounts of peptides to polymeric NPs [40-42]. 
Functionalized NPs with CPPs did not show cytotoxicity at both low and high concentration $\left(5 \mathrm{and} 50 \mu \mathrm{g} \cdot \mathrm{ml}^{-1}\right)$ at $24 \mathrm{~h}$ (Figure 3). At the same incubation time, the commercial drug tested at the low concentration reduced cell viability close to $84 \%$, a value that was significantly different $(\mathrm{p}<0.05)$ to the formulation pAntp-NPs. At a higher concentration, Isoptoflucon increased its cytotoxicity. This may be due to the composition of the commercial drug, which contains excipients such as benzalkonium chloride and polysorbate 80 that decrease cell viability [28,29,43]. After $48 \mathrm{~h}$ treatment, cells incubated with $5 \mu \mathrm{g} \cdot \mathrm{ml}^{-1}$ of the formulations TAT-NPs, pAntp-NPs and Isoptoflucon displayed viability rates close to $80 \%$. At $50 \mu \mathrm{g} \cdot \mathrm{ml}^{-1}$, the cytotoxicity of the commercial drug (Figure $3 \mathrm{~B}$ ) was more evident than that of the formulations TAT-NPs, pAntp-NPs and G2-NPs ( $<0.0001$ ). The G2-NPs formulation had no cytotoxic effects as cell viability was kept around $100 \%$ at both low and high concentrations. At $48 \mathrm{~h}$ viability values were even higher than $100 \%$, which can particularly be due to the nonconjugated sites of the maleimide with G2. The low percentage of MR of G2 in the polymer m-PEG-PLGA in comparison to the other CPPs indicate that the accessible sites of unreacted maleimide may cause an increase in the cellular metabolism and therefore a greater MTT response [44]. Supplementary Figure 4 shows that the formulation without conjugated CPP (FMT-m-PEG-PLGA-NPs) with all the sites of unconjugated maleimide had greater MTT values than G2 $(\mathrm{p}<0.01)$ and the other formulations $(\mathrm{p}<0.0001)$ when assayed in HCE-2 cells at a concentration of $50 \mu \mathrm{g} \cdot \mathrm{ml}^{-1}$ for $48 \mathrm{~h}$.

Functionalized NPs (TAT-NPs, pAntp-NPs and G2-NPs) and the commercial drug (Isoptoflucon) showed similar anti-inflammatory effect $(\mathrm{p}>0.05)$ in the reduction of IL-1 $\beta$ production in cells stimulated with LPS (Figure 4A) ( $\mathrm{p}<0.0001$ ). However, concerning IL-6 (Figure 4B), only G2-NPs triggered comparable effects to the commercial drug ( $\mathrm{p}<0.0001$ ), whereas pAntp-NPs were unable to diminish the high IL-6 expression induced by LPS. All the conjugated NPs significantly decreased the expression of IL-8 (Figure 3C), but none of them managed to reduce it as did Isoptoflucon. Remarkably, the G2-NPs formulation showed a higher effect in the reduction of TNF- $\alpha$ expression than the commercial drug $(p<0.05)$ while TAT-NPs reduced TNF- $\alpha$ levels to the same proportion as Isoptoflucon ( $\mathrm{p}>0.05$ ) (Figure 3D). In contrast, pAntp-NPs promoted greater TNF- $\alpha$ secretion than positive control (LPS-stimulated cells). This effect could probably be related with the mechanism used for cellular internalization of pAntp 43-58. Particularly, the most accepted cellular internalization mechanism for the pAntp $43-58$ is translocation, which would generate excessive destabilization of the cell membrane in HCE-2 cells, activating the inflammatory cascade that lead to increased secretion of certain cytokines. The most prominent effect was evidenced for TNF- $\alpha$ [45].

Overall, this study shows that G2-NPs is the formulation that has a greater effect in the reduction of the proinflammatory cytokines tested, followed by TAT-NPs. The G2 peptide, although not described as a CPP, has been characterized as an antiviral peptide and contain the conserved features of a CPP, such as a 5-30 amino acid sequence rich in Arg residues and positively charged (cationic) [22,46]. This study provides evidence that G2 and TAT allow the internalization of NPs in HCE-2 cells through the creation of transmembrane pores, thus increasing

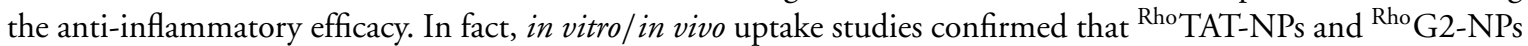
were the formulations that displayed higher internalization scores. In vitro studies in HCE-2 cells revealed that the highest density of internalized NPs, represented by the intensity of emitted fluorescence, was achieved with Rho TAT-NPs (Figure 5). The other formulations were internalized but with a lower extent, without fluorescence accumulation as in the case of Rho TAT-NPs and ${ }^{R h o}$ G2-NPs. At the in vivo level (Figure 6), fluorescence intensity of Rho G2-NPs increased with respect to the in vitro study. This effect could be mainly due to unreacted maleimide (without G2), which can be conjugated with the sulfhydryl groups of mucin present in the lacrimal film [47]. This would increase the residence time in the cornea, helping internalization of the NPs in the ocular internal tissues. Analysis of the nonfunctionalized NPs ( ${ }^{\text {Rho }}$ FMT-m-PEG-PLGA-NPs) also reflects an increase in the internalized NPs signal, that could also be attributed to their interaction with mucin. At last, a certain number of pAntp-NPs manages to reach the posterior segment of the eye (optic nerve) without being retained at the cornea level.

\section{Conclusion}

NPs functionalized with the peptides TAT $_{49-57}$, pAntp $43-58$ and G2 had physicochemical characteristics suitable for ocular topical administration. TAT-NPs and G2-NPs were shown to be the most effective both in vitro and in vivo studies, mainly reducing proinflammatory cytokines. This work demonstrated that NPs conjugated with CPP increase the residence time of the nanostructured system. According to the above reasons, TAT-NPs and G2-NPs could constitute a new noninvasive system for ocular treatment of conditions affecting both the anterior and posterior tissues. 


\section{Future perspective}

In this study, the efficacy of using CPPs conjugated to polymeric NPs to increase the cellular uptake into the posterior segment of the eye has been demonstrated. This research has showed that the presence of G2 linked to FMT-loaded NPs increased the ocular penetration thanks to a further link with mucin glycoproteins. A future investigation, we suggest, be related to explore the physicochemical characteristics of G2-nanostructures system as new noninvasive drug delivery vehicle. Specifically, to study whether the antimicrobial properties of G2 are preserved, increasing the synergistic effect of antimicrobial drugs both at the pharmacological level and increasing their cellular internalization.

\section{Summary points}

- Cell-penetrating peptides linked to polymeric nanoparticles increase the cellular uptake.

- Fluorometholone-loaded polymeric nanoparticles are an effective drug delivery system to improve the treatment of inflammatory eye diseases.

- G2, antiviral peptide, conjugated with polymeric nanoparticles, allowed internalization to the posterior segment of the eye.

- The functionalization of nanoparticles with cell-penetrating peptides decreased the expression of TNF- $\alpha$, IL-6, IL-8.

- TAT-NPs and G2-NPs showed an increasing of fluorescence signal in the human corneal epithelial cells as result of major intercellular accumulation.

- The developed fluorometholone-loaded PEG-PLGA nanoparticles displayed a monodisperse distribution, negative charge and entrapment efficiency close to $99 \%$.

- High performance was obtained using the carbodiimide pathway for the synthesis of rhodamine-PLGA and maleimide-PEG-PLGA polymers.

- In vivo and in vitro uptake studies showed that TAT-NPs and G2-NPs were formulations with the highest density of internalized NPs.

Supplementary data

To view the supplementary data that accompany this paper please visit the journal website at: www.futuremedicine.com/doi/sup $\mathrm{pl} / 10.2217 / \mathrm{nnm}-2019-0201$

\section{Financial \& competing interests disclosure}

The authors would like to thank to the IN2UB project (ART 2018) and to the National Commission for Scientific and Technological Research of Chile (CONICYT) 2014-72150367 for a doctoral grant (RC Gonzalez-Pizarro). M Espina, E Sánchez-López and M-L García belong to 2017SGR-1477 and L Baldoma and J Badia to 2017SGR-1033 from the Government of Catalonia. F Kjeldsen was supported by the European Research Council (ERC) under the European Union's Horizon 2020 Research and Innovation Programme (grant agreement no. 646603). The authors have no other relevant affiliations or financial involvement with any organization or entity with a financial interest in or financial conflict with the subject matter or materials discussed in the manuscript apart from those disclosed.

No writing assistance was utilized in the production of this manuscript.

Ethical conduct of research

The animal work involved in the in vivo ocular uptake study gained the approved by the ethics committee of the University of Barcelona according to ethical guidelines of the European Community Council Directive 86/609/EEC and the procedures established by the Department of Agriculture, Branch and Fisheries of the Government of Catalonia. The authors state that they have obtained appropriate institutional review board approval or have followed the principles outlined in the Declaration of Helsinki for all human or animal experimental investigations.

\section{References}

Papers of special note have been highlighted as: $\bullet$ of interest; $\bullet \bullet$ of considerable interest

1. Harthan J, Fromstein S, Morettin C, Opitz D. Diagnosis and treatment of anterior uveitis: optometric management. Clin. Optom. 8, 23-35 (2016).

2. Samudre SS, Lattanzio FA, Williams PB, Sheppard JD. Comparison of topical steroids for acute anterior uveitis. J. Ocul. Pharmacol. Ther. 20(6), 533-547 (2004).

3. Ali J, Fazil M, Qumbar M, Khan N, Ali A, Ali A. Colloidal drug delivery system: amplify the ocular delivery. Drug Deliv. 23(3), 700-716 (2016). 
4. Yasin MN, Svirskis D, Seyfoddin A, Rupenthal ID. Implants for drug delivery to the posterior segment of the eye: a focus on stimuli-responsive and tunable release systems. J. Control. Release 196, 208-221 (2014).

5. Kim Y-H, Jung J-C, Jung S-Y, Yu S, Lee KW, Park YJ. Comparison of the efficacy of fluorometholone with and without benzalkonium chloride in ocular surface disease. Cornea 35(2), 234-242 (2016).

6. Jee D, Park SH, Kim MS, Kim EC. Antioxidant and inflammatory cytokine in tears of patients with dry eye syndrome treated with preservative-free versus preserved eye drops. Invest. Opthalmol. Vis. Sci. 55(8), 5081-5089 (2014).

7. Bielory BP, Perez VL, Bielory L. Treatment of seasonal allergic conjunctivitis with ophthalmic corticosteroids: in search of the perfect ocular corticosteroids in the treatment of allergic conjunctivitis. Curr. Opin. Allergy Clin. Immunol. 10(5), 469-477 (2010).

8. Shokoohi-Rad S, Daneshvar R, Jafarian-Shahri M, Rajaee P. Comparison between betamethasone, fluorometholone and loteprednol etabonate on intraocular pressure in patients after keratorefractive surgery. J. Curr. Ophthalmol. 30(2), 130-135 (2018).

9. Pinto-Fraga J, López-Miguel A, González-García MJ et al. Topical fluorometholone protects the ocular surface of dry eye patients from desiccating stress: a randomized controlled clinical trial. Ophthalmology 123(1), 141-153 (2016).

10. Silva-Abreu M, Calpena AC, Espina M et al. Optimization, biopharmaceutical profile and therapeutic efficacy of pioglitazone-loaded PLGA-PEG nanospheres as a novel strategy for ocular inflammatory disorders. Pharm. Res. 35(1), 11 (2018).

11. Mandal A, Bisht R, Rupenthal ID, Mitra AK. Polymeric micelles for ocular drug delivery: from structural frameworks to recent preclinical studies. J. Control. Release 248, 96-116 (2017).

12. Kalam MA. The potential application of hyaluronic acid coated chitosan nanoparticles in ocular delivery of dexamethasone. Int. J. Biol. Macromol. 89, 559-568 (2016).

13. Reimondez-Troitiño S, Csaba N, Alonso MJ, de la Fuente M. Nanotherapies for the treatment of ocular diseases. Eur. J. Pharm. Biopharm. 95, 279-293 (2015).

14. Gonzalez-Pizarro R, Carvajal-Vidal P, Halbault Bellowa L, Calpena AC, Espina M, García ML. In-situ forming gels containing fluorometholone-loaded polymeric nanoparticles for ocular inflammatory conditions. Colloids Surf. B Biointerfaces. 175, 365-374 (2019).

15. Guengerich FP. Intersection of the roles of cytochrome P450 enzymes with xenobiotic and endogenous substrates: relevance to toxicity and drug interactions. Chem. Res. Toxicol. 30(1), 2-12 (2017).

16. Aukunuru JV, Sunkara G, Bandi N, Thoreson WB, Kompella UB. Expression of multidrug resistance-associated protein (MRP) in human retinal pigment epithelial cells and its interaction with BAPSG, a novel aldose reductase inhibitor. Pharm. Res. 18(5), 565-572 (2001).

17. Vasconcelos A, Vega E, Pérez Y, Gómara MJ, García ML, Haro I. Conjugation of cell-penetrating peptides with poly(lactic-co-glycolic acid)-polyethylene glycol nanoparticles improves ocular drug delivery. Int. J. Nanomedicine 10, 609-631 (2015).

- Two methods of functionalization of nanoparticles with cell-penetrating peptides.

18. Melikov K, Chernomordik LV. Arginine-rich cell penetrating peptides: from endosomal uptake to nuclear delivery. Cell. Mol. Life Sci. 62(23), 2739-2749 (2005).

19. Pescina S, Ostacolo C, Gomez-Monterrey IM et al. Cell penetrating peptides in ocular drug delivery: state of the art. J. Control. Release 284, 84-102 (2018).

-• Review of cell-penetrating peptides used for ocular internalization.

20. Guidotti G, Brambilla L, Rossi D. Cell-penetrating peptides: from basic research to clinics. Trends Pharmacol. Sci. 38(4), 406-424 (2017).

21. Bahnsen JS, Franzyk H, Sandberg-Schaal A, Nielsen HM. Antimicrobial and cell-penetrating properties of penetratin analogs: effect of sequence and secondary structure. Biochim. Biophys. Acta 1828(2), 223-232 (2013).

22. Delcroix M, Riley LW, Delcroix M, Riley LW. Cell-penetrating peptides for antiviral drug development. Pharmaceuticals 3(3), 448-470 (2010).

23. Tiwari V, Liu J, Valyi-Nagy T, Shukla D. Anti-heparan sulfate peptides that block herpes simplex virus infection in vivo. J. Biol. Chem. 286(28), 25406-25415 (2011).

24. Ali MM, Karasneh GA, Jarding MJ, Tiwari V, Shukla D. A 3-O-sulfated heparan sulfate binding peptide preferentially targets herpes simplex virus 2-infected cells. J. Virol. 86(12), 6434-6443 (2012).

-• Study evidencing that the antiviral peptide G2 shows characteristics of cell-penetrating peptides.

25. Park PJ, Antoine TE, Farooq AV, Valyi-Nagy T, Shukla D. An investigative peptide-acyclovir combination to control herpes simplex virus type 1 ocular infection. Invest. Opthalmol. Vis. Sci. 54(9), 6373 (2013).

26. Lin WJ, Liu WJ. Polymeric nanoparticles conjugate a novel heptapeptide as an epidermal growth factor receptor-active targeting ligand for doxorubicin. Int. J. Nanomedicine 7, 4749 (2012).

27. Gonzalez-Pizarro R, Silva-Abreu M, Calpena AC, Egea MA, Espina M, García ML. Development of fluorometholone-loaded PLGA nanoparticles for treatment of inflammatory disorders of anterior and posterior segments of the eye. Int. J. Pharm. 547(1-2), 338-346 (2018). 
28. Khoh-Reiter S, Jessen BA. Evaluation of the cytotoxic effects of ophthalmic solutions containing benzalkonium chloride on corneal epithelium using an organotypic 3-D model. BMC Ophthalmol. 9, 5 (2009).

29. Czajkowska-Kośnik A, Wolska E, Chorążewicz J, Sznitowska M. Comparison of cytotoxicity in vitro and irritation in vivo for aqueous and oily solutions of surfactants. Drug Dev. Ind. Pharm. 41(8), 1232-1236 (2015).

30. Rezaei A, Varshosaz J, Fesharaki M, Farhang A, Jafari SM. Improving the solubility and in vitro cytotoxicity (anticancer activity) of ferulic acid by loading it into cyclodextrin nanosponges. Int. J. Nanomedicine 14, 4589-4599 (2019).

31. Valeur E, Bradley M. Amide bond formation: beyond the myth of coupling reagents. Chem. Soc. Rev. 38(2), 606-631 (2009).

32. Hermanson G. The chemistry of reactive groups. In: Bioconjugate Techniques (2nd Edition). Hermanson G (Ed.). Academic Press, London, UK 169-212 (2008).

33. Li Y-P, Pei Y-Y, Zhang X-Y et al. PEGylated PLGA nanoparticles as protein carriers: synthesis, preparation and biodistribution in rats. J. Control. Release 71(2), 203-211 (2001).

34. Zhang Q, Zhu J, Song L et al. Engineering magnetic-molecular sequential targeting nanoparticles for anti-cancer therapy. J. Mater. Chem. B 1(46), 6402-6410 (2013).

35. Pereira ED, Cerruti R, Fernandes E et al. Influence of PLGA and PLGA-PEG on the dissolution profile of oxaliplatin. Polimeros 26(2), 137-143 (2016).

- Proper characterization of PLGA and PEG-PLGA polymers.

36. Sánchez-López E, Ettcheto M, Egea MA et al. Memantine loaded PLGA PEGylated nanoparticles for Alzheimer's disease: in vitro and in vivo characterization. J. Nanobiotechnology 16(1), 32 (2018).

37. Cano A, Ettcheto M, Espina M et al. Epigallocatechin-3-gallate loaded PEGylated-PLGA nanoparticles: a new anti-seizure strategy for temporal lobe epilepsy. Nanomedicine 14(4), 1073-1085 (2018).

38. Ali Y, Lehmussaari K. Industrial perspective in ocular drug delivery. Adv. Drug Deliv. Rev. 58(11), 1258-1268 (2006).

39. Stolnik S, Garnett MC, Davies MC et al. The colloidal properties of surfactant-free biodegradable nanospheres from poly $(\beta$-malic acid-co-benzyl malate)s and poly(lactic acid-co-glycolide). Colloids Surf. A Physicochem. Eng. Asp. 97(3), 235-245 (1995).

40. Ravi S, Krishnamurthy VR, Caves JM, Haller CA, Chaikof EL. Maleimide-thiol coupling of a bioactive peptide to an elastin-like protein polymer. Acta Biomater. 8(2), 627-635 (2012).

41. Northrop BH, Frayne SH, Choudhary U. Thiol-maleimide "click" chemistry: evaluating the influence of solvent, initiator, and thiol on the reaction mechanism, kinetics, and selectivity. Polym. Chem. 6(18), 3415-3430 (2015).

42. Sazano G, Torchilin W. Intracellular delivery of nanoparticles with cell penetrating peptides. In: Cell-penetrating peptides: methods and protocols. Langel Ü (Ed.). Humana Press, Totowa, NJ, USA, 357-386 (2015).

43. Liu Z, Li J, Nie S, Liu H, Ding P, Pan W. Study of an alginate/HPMC-based in situ gelling ophthalmic delivery system for gatifloxacin. Int. J. Pharm. 315(1), 12-17 (2006).

44. Ali B, Kanda Kupa LD, Heluany CS et al. Cytotoxic effects of a novel maleimide derivative on epithelial and tumor cells. Bioorg. Chem. 72, 199-207 (2017).

45. Drin G, Déméné H, Temsamani J, Brasseur R. Translocation of the pAntp peptide and its amphipathic analogue AP-2AL. Biochemistry 40, 1824-1834 (2001).

46. Splith K, Neundorf I. Antimicrobial peptides with cell-penetrating peptide properties and vice versa. Eur. Biophys. J. 40(4), 387-397 (2011).

- $\quad$ Relationship between cell-penetrating peptides and antimicrobial peptides.

47. Tonglairoum P, Brannigan RP, Opanasopit P, Khutoryanskiy VV. Maleimide-bearing nanogels as novel mucoadhesive materials for drug delivery. J. Mater. Chem. B 4(40), 6581-6587 (2016).

-• Excellent example of increasing ocular adhesiveness with maleimide. 